\title{
PrOMor: A Proposed Prototype of V2V and V2I for Crash Prevention in the Moroccan Case
}

\author{
Zakaria Sabilf Aouatif Amine
}

Ibn Tofail University, ILM Department, ENSA, Kenitra, 14000, Morocco

\begin{tabular}{l} 
A R T I C L E I N F O \\
\hline Article history: \\
Received: 03 October, 2020 \\
Accepted: 02 January, 2021 \\
Online: 15 January, 2021
\end{tabular}

Keywords:

Vehicular Communications

Road Safety

$\mathrm{V} 2 \mathrm{~V}$

V2I

VANET

Connected Vehicles

\begin{abstract}
A B S T R A C T
Road safety has become an object of research and many research institutes have invested in this field because a lot of people die and many others are injured every year due to road accidents. The deployment of wireless communication technologies for vehicular networks can considerably improve road safety. It can enable new services such as traffic management, collision detection, and additional communication ease between moving vehicles. This paper presents a complete implementation of Vehicle to Vehicle $(V 2 \mathrm{~V})$ and Vehicle to Infrastructure (V2I) communications. Raspberry Pi boards, ultrasonic sensor, infrared obstacle detector, and line follower sensors are used in order to implement the complete prototype. The results show the usefulness of this road safety prototype named PrOMor (Prevention of Obstacles in Morocco). Based on these results, it can be concluded that the presented scenarios can be applied to the field of road safety related to the Moroccan case. This should reduce the number of accidents and save more human lives.
\end{abstract}

\section{Introduction}

This paper is an extension of work originally presented in the International Conference on Computational Intelligence and Knowledge Economy (ICCIKE) [1]. In the current work, the authors will deal with the whole vehicular communication system to address road safety issues, especially in the Moroccan case.

Since millions of people die every year and many more are injured because of car accidents, road safety has been gaining importance in recent years. Statistics [2] show that road traffic casualties in the world amount to 1.17 million per year. According to the World Health Organization (WHO), road accidents claimed the lives of 1.25 million people in 2013. In 2014, more than a million accidents occurred in Europe, killing 25900 people and 1.4 million wounded. In 2017, 3,499 deaths were recorded on Moroccan roads, against 3,593 in 2016, a small decrease of $2.6 \%$ year-on-year. While statistics show a slight advance in road safety, they hide other, more disturbing realities 1 These statistics are blatant, so the Ministry of Equipment, Transport, Logistics, and Water (METLE) thought to launch research projects in partnership with Moroccan universities and the National Center for Scientific and Technical Research (CNRST) in order to reduce the number of victims. This project based on the detection and the anticipation of the accidents aims to help to reduce the accident rate using the V2V and V2I communications to detect obstacles and prevent the crash in the Moroccan case. According to the traffic accident statistics carried out by the METLE in 2016 [3], there were 80680 accidents caused by obstacles.

Today the road network in Morocco [4], whose routes are traditionally hierarchical in the main, collector, and service according to the function they fulfill for the network itself, is not in adequacy with its urban environment and the needs of the inhabitants and users. Thus, for example, very wide paths designed for cars can pass through neighborhoods endangering pedestrians who go there to shop, go to school or work, or simply go to the neighbor. It must be recognized that, particularly in dense urban areas, the lanes fulfill a multiplicity of functions that go beyond the simple role of channeling private vehicles (social functions, economic, leisure, etc.).

To put a stop to this massacre, in addition to legislative measures, digital technologies will play a major role. The automation/semiautomation of vehicles will limit the human error, responsible for the majority of road accidents. Manufacturers are working on connected vehicles that will be equipped with several sensors. They will be able to interpret their environment in a dynamic way to alert drivers of the various hazards which could be found on the road.

In this context, the main purpose of Intelligent Transportation

${ }^{*}$ Corresponding Author: Zakaria Sabir, University Campus P. O. Box 241, Kenitra, Morocco, zakaria.sabir@uit.ac.ma

${ }^{1}$ Leconomiste, https://www.leconomiste.com (accessed Jul. 08, 2019) 
Systems (ITS) is to improve transportation safety, increase productivity, reduce traffic jams and reduce the number of accidents on our future roads, thanks to the use of advanced information technology. Nonetheless, the big challenge is to constitute an interdependent environment that merges all the technologies and can solve a variety of transportation problems. If the electronic, computing, and networking technologies are well integrated, the mobility will be more efficient, the roads will be safer and the impact on the environment will be minimized [5].

These systems will allow vehicles to communicate their relative positions, for example, to signal the presence of another vehicle in a blind spot. Mainly, it will be connected to various sensors inside the vehicle: stability, hazard warning lights, airbags, and other diagnostic tools. Therefore, a vehicle can automatically communicate to others the presence of a slippery roadway, if it is down or in an accident. The other drivers will then adjust their approach in the concerned area. The ITS will also help to know the position of emergency vehicles (ambulances, firefighters, police) on approach. Their only sirens today give little information on their provenance and direction. Civilian vehicles will then clear the way more efficiently using the ITS.

One of the most important components of ITS, which has been proposed to address challenges in the transportation surface is the connected vehicle system. It is a hopeful technology that uses wireless communication. In order to treat transportation problems, connected vehicle system will use Vehicle to Vehicle (V2V) and Vehicle to Infrastructure (V2I) communications [6], [7].

Different definitions have been given recently for a "connected" vehicle. A definition given at the 2013 Automotive News World Congress by IBM, identifies a connected vehicle as "a vehicle capable of seamless integration with multiple systems, connecting consumers to the digital world". More precise definitions include all the other connections of a modern vehicle: according to the US Department of Transportation (USDOT), "Connected vehicle applications provide connectivity between vehicles to prevent accidents, between vehicles and infrastructure, in order to generate safety, mobility and environmental benefits; between vehicles, infrastructure and wireless devices to provide continuous real-time connectivity to all users of the system" [8].

Different studies have already tried to develop prototypes of connected vehicles and systems that support V2V and V2I communications. But, as will be explained later, those systems were developed in foreign countries and cannot be applied in Morocco. Thus, the authors thought of a system that will fit the Moroccan case. This paper presents the implementation of a vehicular communication environment using both V2V and V2I technologies. This system is the first of its kind in Morocco. It requires a real test on real cars, but the authors carried out the tests on two robots only and it will be spread over a large number of cars in the real case, the used robots are based on Raspberry Pi-based mini cars kits, which were personalized by adding different features and other sensors in order to get to the target. The remainder of the paper is organized into four sections: Section 2 explain the proposed system. Experiments results will be presented and discussed in Section 3, while Section 4 concludes the paper.

\section{Related works}

This work is inspired by several prior studies that used various technologies on connected vehicle networks. A summary of related works is discussed in this section.

A recent work [9] explored the future beneficiaries of $5 \mathrm{G}$ and selected the conditions where $5 \mathrm{G}$ can make an effect. Particularly, three use-cases were considered: V2X (Vehicle-to-Everything Communication), Healthcare, and Drones. The authors investigated and emphasized some imperfections and failures of the current cellular topologies regarding the mentioned use-cases, then they determined how $5 \mathrm{G}$ will surmount those failures.

In [10], the author described the multi-class zone ITS communication scheme regarding short periodical communications and real-time for vehicle safety in intersections. In the proposed scheme, two types of areas around an intersection were designed, the nearest area and quasi-nearest area. In the first one, the communication of vehicles is done every $20 \mathrm{~ms}$ with a base station. While in the second one, vehicles make reservations for the communication for the first type and also communicate with the base station for safety. The required frequency bandwidth needed to realize the proposed design was shown in the simulation results.

A strategy of centralized and localized data congestion control is proposed in [11]. It uses RSUs (Road-Side Units) at intersections to control data congestion. It includes three entities for clustering messages, detecting congestion, and controlling data congestion. In order to detect data congestion in the channels, the strategy measures the channel usage. The messages are refined, assembled, and then grouped using algorithms of machine learning. Simulation results affirmed the efficacy of the proposed strategy in terms of improving the delay, packet loss ratio, and throughput.

Another system is presented in [12], it is an integrated vehicular system that uses an integrated V2I and V2V communication model improved with an information management system. The aim is the management, accumulation, and arrangement of context-aware information on driver location and traffic. The concept of smart roads is featured in the vehicular system. Significant information and all the risks related to the safety and detected by vehicles are managed by the infrastructure and adjusted to the driver's choices and the vehicle's context. The authors implemented the required software and used real hardware for infrastructure as well as a real vehicle to build the entire system.

Other authors [13] proposed to substitute the currently proposed standard (802.11p, DSRC/WAVE) to build an inter-vehicle communication system. They suggested using android smartphones along with Wi-Fi to replace the OBU (On-Board Unit) on consumer vehicles and to enable thereby $\mathrm{V} 2 \mathrm{I}$ and $\mathrm{V} 2 \mathrm{~V}$ communications. The system is compatible with android devices with the 2.3 version and above. The users will then acquire an OBU that communicate with the nearby vehicles to broadcast an emergency alert or to warn about an accident. Experiment results showed the ease of use of the system, its efficiency, and its compatibility with Android devices.

In [14], the author checked out the performance of Het-Net (Heterogeneous Networks) consisting of LTE, DSRC, and Wi-Fi technologies for V2I and V2V communications. To enable Het-Net for vehicular communication applications, the authors developed an application layer handoff method. It was used to collect traffic 
data and to warn about the collision. This research proved through the conducted field studies the usefulness of Het-Net in vehicular communications. Simulation experiments were run using a big number of connected vehicles including LTE and DSRC Het-Net scenarios. The results in terms of packet delivery error and latency from simulation were found to be identical to the field experiment results.

In this paper [15], the authors used data from the University of Michigan Safety Pilot Model Deployment project to analyze the performance of DSRC. They used selected road-side equipment and 1050 vehicles to evaluate the packet delivery ratio and the effective range of V2I communications. They have also studied the impact of some environmental factors like weather, trees, road elevation, buildings, and so on. The results are useful in the development of DSRC communication models and guiding future DSRC equipment placement.

In [16], the author used a distributed message delivery platform to develop a strategy. The aim is the creation of an effective and lowlatency distributed message delivery system for connected vehicle applications. The strategy can transform the unstructured data into labeled topics for large consumers like data centers, mobile devices, and connected vehicles. The performance of the strategy was evaluated using a prototype and Apache Kafka, an open-source delivery system, and comparing its efficiency with the latency qualifications of connected vehicle applications. The experiments disclosed the correspondence of the measured latencies with USDOT (U.S. Department of Transportation) recommendation for connected vehicle applications.

In this paper, different from those studies, the proposed system considers employing vehicular communications in the Moroccan case. Authors have focused on the V2V and V2I communications since the conventional scheme can't be applied in Morocco. Taking into consideration the situation in Morocco and many other differences in comparison to other countries, a foreign system cannot work well for Morocco, the adjustment is required and many factors are to bear in mind. The architecture of Moroccan cities is different from other countries, in the big cities, for example, there are administrative regions, industrial regions, residential districts, the old medina, the new medina, etc. Other factors to take into consideration are culture and environment. The driver behavior and the usage of technology by the population need to be considered. Road conditions, alleys in one or two directions, signs boards, and narrow alleys also have to be considered.

The authors started with the realization using mini cars on a model and they have successfully achieved the goal. In the next step, they will move on to real scenarios with real cars in order to specify the necessary adjustments. The proposal represents also a contribution to the development of smart cities as there is already a trend for smart cities in Morocco. In June 2013, e-Madina was born in APEBI, the Moroccan federation of information technologies, telecommunications, and offshoring. e-Madina is a Smart Cities Cluster that works to make the city of Casablanca more attractive and more efficient using digital technologies and available material and immaterial resources. In March 2017, the government launched the "Cité Mohammed VI Tanger Tech" project, a smart city that will extend over 200 hectares within 10 years. Funding for the operation is estimated at \$ 1 billion. Nearly 200 companies operating in the automotive, aeronautic, textile, electronics, and machine tool industries will set up there.

To the best of their knowledge, authors believe this is the first paper that deals with vehicular communications in the Moroccan case, and this is one of the reasons that made this work chosen, accepted, and financed by the METLE and the CNRST.

\section{Proposed system}

Connected vehicles are able to revolutionize the current traveling style by creating a protected and interoperable wireless communications network, a system that involves several elements like cars, traffic lights, buses, and trains. Technologies of connected vehicles aim to address some serious challenges in the transportation fields, especially in environment, mobility, and safety.

The purpose of this work belongs to the last field, which is road safety, especially in the Moroccan case to solve the problems cited above, since the conventional scheme can't be applied in Morocco as it is as explained previously. Authors propose three safety scenarios which will be used to alert Moroccan drivers in different situations, in order to decrease the probability of road accidents and to stay away from collision scenes that repeatedly happen between vehicles and pedestrians, animals, trees, and such other objects. These scenarios are based on reel time information and use V2V and V2I modes. Roadside units and vehicles exchange information that will be very useful to anticipate a hazardous situation. This information is delivered to Moroccan drivers in order to help them avoid the danger presented in unstructured roads.

Taking into consideration the statistics presented in [3], the first scenario can notify a driver of a hard-braking vehicle in the path ahead. For example, three vehicles are traveling in the same lane (see Fig. 1(a)); the driver of the third vehicle can't see the first vehicle because it's being blocked by the second one, which is located directly in front of him. Unexpectedly, the first vehicle slams on its brakes. Thanks to V2V communication, the third vehicle is able to provide a warning of the hard-braking vehicle ahead. This warning will help the driver to drive safely and avoid a potential crash, as can be seen in Fig. 11(a).

The second and the third scenarios aim to notify a driver of a special traffic condition in the path ahead. Whenever a traffic event is detected (accident, traffic jam, pedestrian crossing the road, animal, road work...), the driver is advised to slow down, change the lane, and take another route. Using V2V communication, the warning notification is transferred by another vehicle ahead, which has previously detected the problem of the related traffic event. V2I communication also was used for the same purpose (see Fig. 1 (b)). In this case, the warning notification is transferred by the RSU placed on the border of the road instead. The location of the RSU depends on the number of accidents recorded in this area and given by the METLE Ministry.

The diagrams in Fig. 2 summarize the logical flow of the methodology in each car. In this scenario, V1 and V2 which are equipped with a Raspberry Pi ran on a straight path using line follower sensors. V1 keeps using the infrared sensor along the way in order to detect any obstacle before the destination. If V1 detects an obstacle, it will stop and send the data as an alert to V2. Similarly, 
the latter continues on the path to the destination unless it receives an alert from V1. If so, it will stop and change the road to avoid the obstacle and get to the destination. a-1.pdf

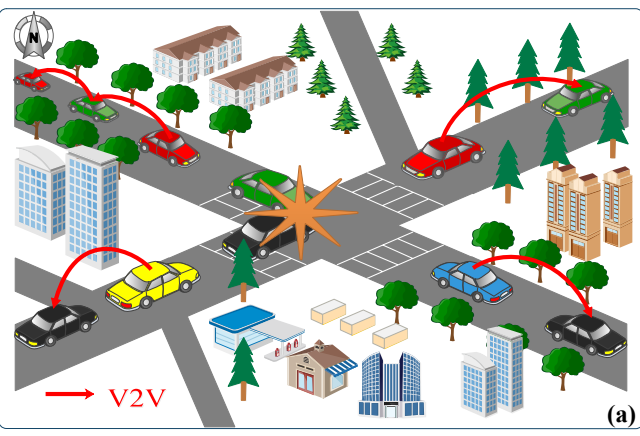

b-1.pdf

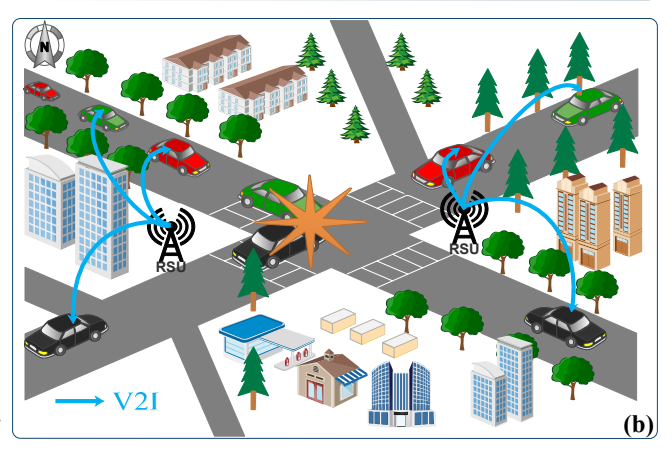

Figure 1: Operation of the system, (a) represents V2V mode and (b) represents V2I mode

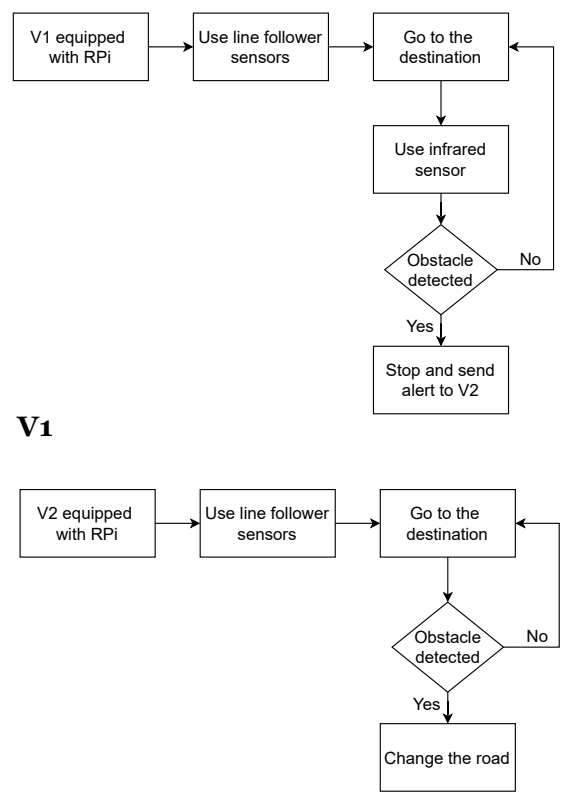

V2

Figure 2: Flowchart for V2V communication.

Reducing possible points of conflict between vehicles and with other users is a common practice of road safety. For this, it is necessary to act in particular on the geometry of the path and the management of the priorities, especially for the zones of intersection and crossing with the presence of different users. According to the compendium of statistics of road traffic accidents [3], carried out in 2017 by the METLE, 14998 accidents were recorded in the intersections. Thus, taking into account the statistics, the authors proposed the METLE concerning the locations of the RSUs concerning the areas likely to have accidents in the city of Kenitra (as can be seen in Fig. 3). The communication between these RSUs and also between these RSUs and the vehicles in the area can help to avoid the slowed traffic during a rush hour as shown in Fig 3

This communication can also help to avoid accidents in hazardous regions especially unstructured ones. A real case is shown in Fig. 4 where the area with diagonal lines was recently transformed into a roundabout, but it was not well adjusted to represent the roundabout. Therefore, someone who is a stranger to the city can take the road straight while it is forbidden. This can cause accidents in this area, as shown in figure 3 .

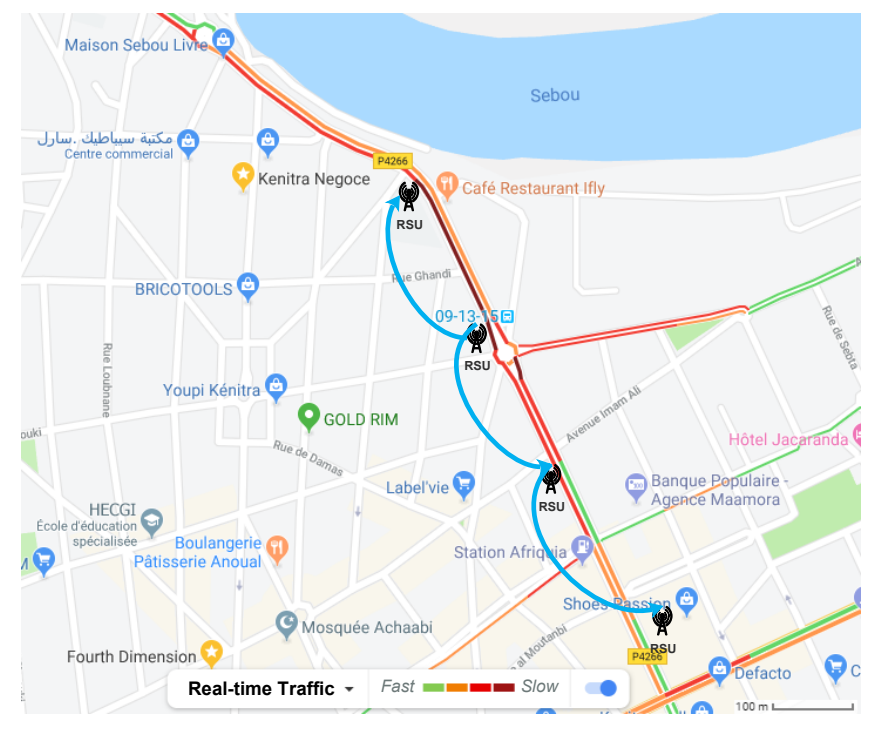

Figure 3: The locations of the RSUs to help mitigate the congestion in Kenitra city

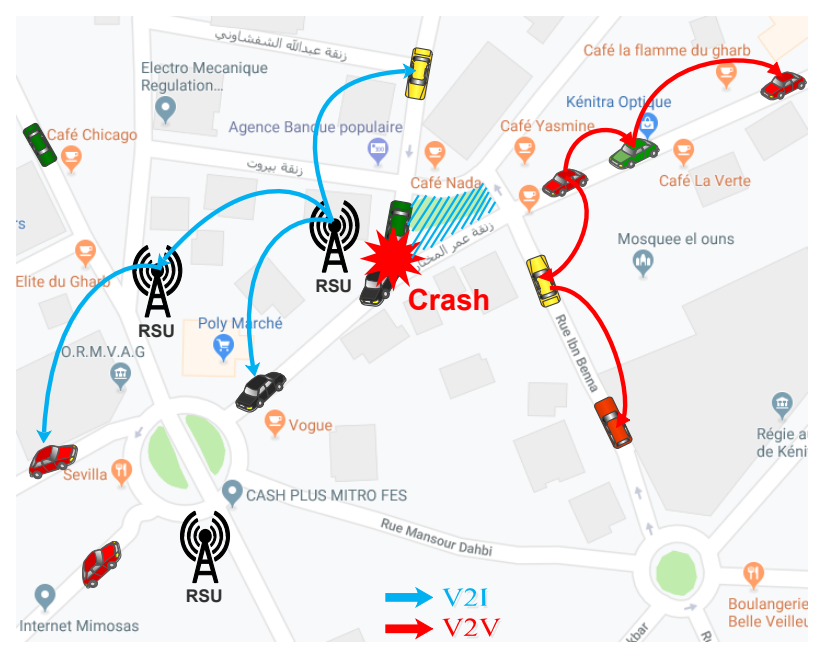

Figure 4: A Real case of an unstructured area in Kenitra city

In order to model the system, the authors proposed two algorithms. One on the client-side and the other on the server-side. Both algorithms start by importing the necessary modules and assigning 
pins numbers. The next step is to create a socket so the two cars can communicate. After that, various methods used in the algorithms are defined :

- setup(): sets the setup of the system (variables, frequency, sensor modes ...).

- setSpeed(): manipulates the speed of the vehicle and handles the error related to the trajectory.

- stop(): stops the motors of the vehicle.

- read_sensors(): reads the line follower sensors and stores a variable related to the error of the trajectory.
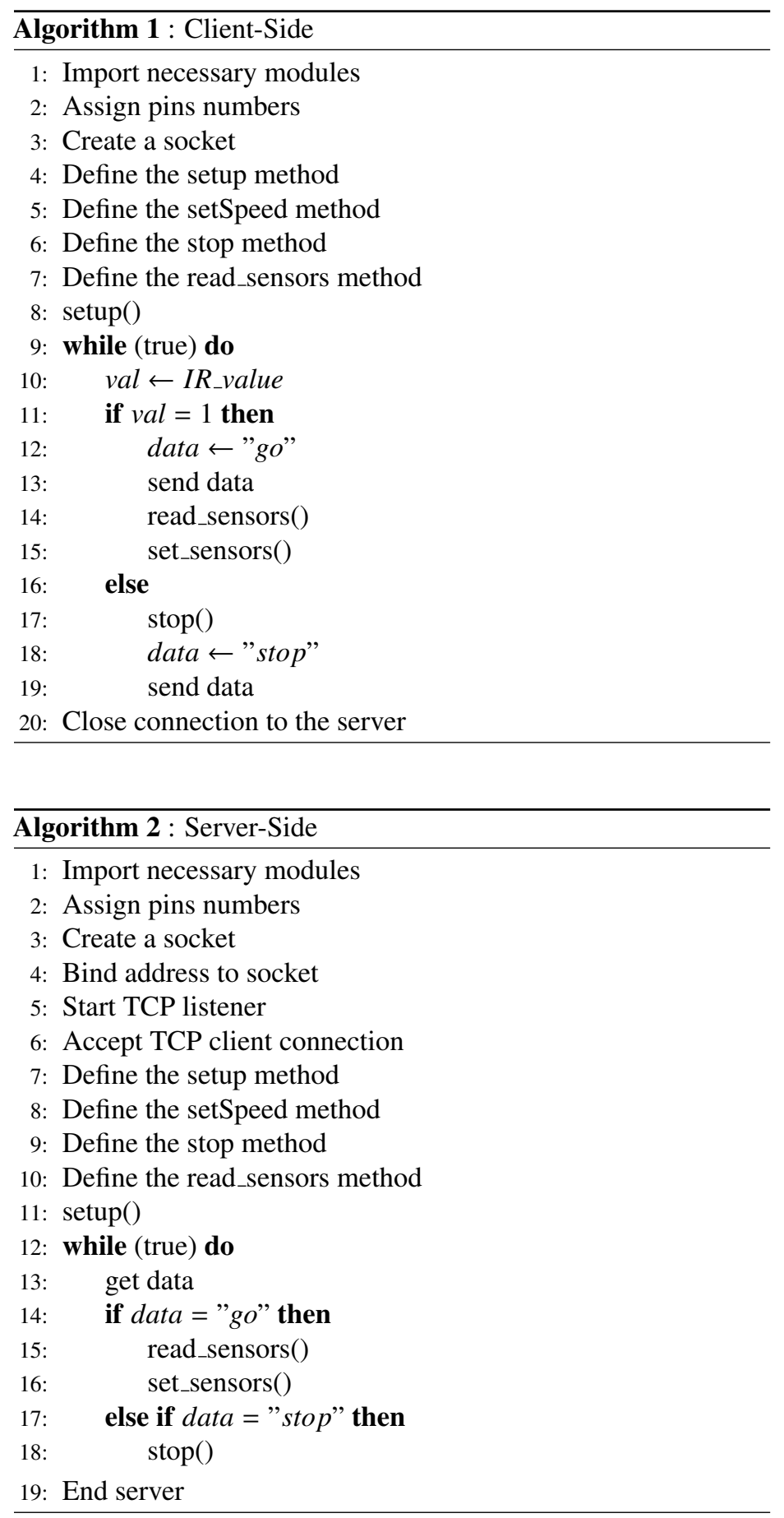

An infinite loop is necessary to keep reading data from sensors, sending it by the client, and receiving it by the server. If the infrared sensor (located on the client side) detected an obstacle, the IR_value receives the value " 0 ". The client sends then the data to the server which will stop immediately. Else, the IR_value remains in " 1 ". The client sends then the data to the server which will continue the path to get to the destination. The proposed algorithms are presented in Algorithm 1 and 2 .

Table 1 presents a comparison of the proposed system with other studies.

\section{Experimentation}

\subsection{Experimental setup}

In the validation step, the authors preferred to use prototypes in the tests before applying the system to real cars. The experiments were conducted using two mini cars from Sunfounder ${ }^{2}$ (Fig. 5 to develop the prototype system. Each car has a Raspberry Pi 3 B+ with basic necessary configuration to enable communication and control movements and sensors. A third Raspberry Pi 3 B board was used to play the role of the RSU. The used boards consist of ARM Cortex-A53 quad-core, which is operating at $1.4 \mathrm{GHz}$ for the model $\mathrm{B}+$ and $1.2 \mathrm{GHz}$ for the model $\mathrm{B}$. They both have a memory of $1 \mathrm{~GB}$ (RAM), 40GPIO, Audio jack, Ethernet port, Camera interface, HDMI port, Display interface, 4 USB port 2.0, and micro SD slot. The two devices are powered by $5 \mathrm{~V} / 2.5 \mathrm{~A}$ via a micro USB port. Raspbian was chosen as an operating system. It is installed and boots from the micro SD card.

Both the cars integrate $\mathrm{Wi}-\mathrm{Fi}$, so they are able to communicate within an ad hoc network while moving in the test zone. The movement of the cars is powered by the two rear wheels using a DC motor driver. The cars came also with a USB camera, a step-down DC-DC converter module, and a PCA9685-based servo controller. The camera is not used in the current prototype, but it is used to prevent pre-crash by detecting pedestrians in another part of the same project SAFEROAD [21].

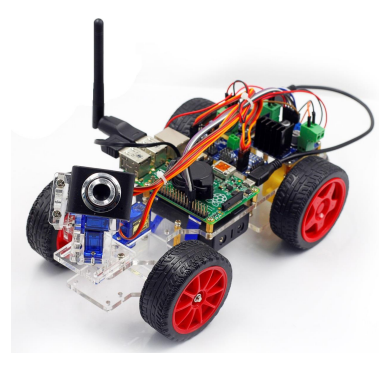

Figure 5: Sunfounder mini car

Since the original car kit didn't come with all the hardware needed to run the tests, the authors used some other sensors to complete the prototype, as can be seen in ((a) and (b)) Fig. 6 . Five line follower sensors were added below each car, so they help the car following the line (road), in addition to detectors that have the ability to sense the existence of an obstacle in the path.

${ }^{2}$ Sunfounder, https://www.sunfounder.com/learn/category/Smart-Video-Car-for-Raspberry-Pi.html/ (accessed Jul. 15, 2019) 
Table 1: Comparison of the current work with other studies

\begin{tabular}{|c|l|l|l|l|l|l|}
\hline Study & $\begin{array}{l}\text { Communi- } \\
\text { cation } \\
\text { Mode }\end{array}$ & $\begin{array}{l}\text { Implemen- } \\
\text { tation }\end{array}$ & Tools & Scenario & Purpose & Special Case \\
\hline$[17]$ & V2V & Real Time & $\begin{array}{l}\text { RPi; Ultrasonic } \\
\text { sensors; Audible } \\
\text { Alarm; GPS Sensor; } \\
\text { RF Module }\end{array}$ & $\begin{array}{l}\text { Blind Spot Detec- } \\
\text { tion }\end{array}$ & $\begin{array}{l}\text { Improving Traffic } \\
\text { Congestion }\end{array}$ & Not specified \\
\hline$[18]$ & V2V & Real Time & $\begin{array}{l}\text { OsmAnd; Android } \\
\text { Devices; GRCBox }\end{array}$ & $\begin{array}{l}\text { Displaying loca- } \\
\text { tion of relevant ve- } \\
\text { hicles }\end{array}$ & $\begin{array}{l}\text { Warning about } \\
\text { emergency } \\
\text { vehicles }\end{array}$ & Not specified \\
\hline$[19]$ & V2V & Real Time & $\begin{array}{l}\text { RPi; Controller; IR } \\
\text { Sensor }\end{array}$ & $\begin{array}{l}\text { Autonomous } \\
\text { Driving (level 3) }\end{array}$ & $\begin{array}{l}\text { Smooth Traffic } \\
\text { Flow }\end{array}$ & Not specified \\
\hline$[20]$ & V2V and & Real Time & $\begin{array}{l}\text { ECU sensors, Ar- } \\
\text { duino; GPS sensor; } \\
\text { LM393 speed sensor } \\
\text { module; CAN com- } \\
\text { munication module; } \\
\text { Wi-Fi modem }\end{array}$ & $\begin{array}{l}\text { Detect sudden } \\
\text { of the vehicles } \\
\text { (speed, location, } \\
\text { brake position) }\end{array}$ & $\begin{array}{l}\text { Help in Advanced } \\
\text { Driver Assistance } \\
\text { System (ADAS) }\end{array}$ & Not specified \\
\hline This paper & $\begin{array}{l}\text { V2V and } \\
\text { V2I }\end{array}$ & Real Time & $\begin{array}{l}\text { RPi mini cars; IR sen- } \\
\text { sor; Line Followers }\end{array}$ & $\begin{array}{l}\text { Obstacle Detec- } \\
\text { tion }\end{array}$ & $\begin{array}{l}\text { Preventing Acci- } \\
\text { dents }\end{array}$ & Moroccan Case \\
\hline
\end{tabular}

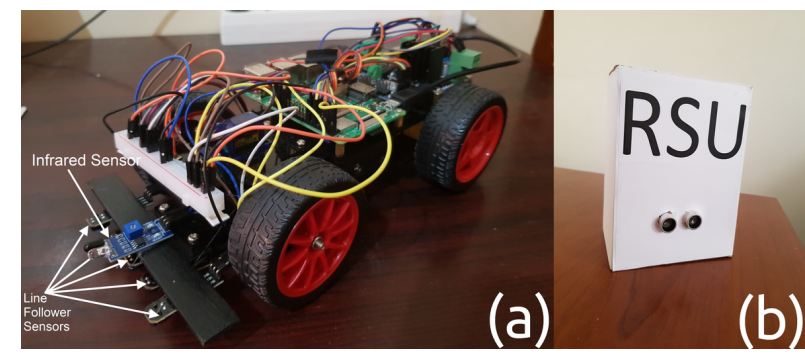

Figure 6: The prototypes, (a) Robot \& (b) RSU

One infrared obstacle detector was used at the front of the first car, in addition to one ultrasonic sensor used in the RSU. The specifications of the sensors are given in Table 2 .

Table 2: The specifications of the used sensors

\begin{tabular}{|c|l|l|l|}
\hline Sensor name & $\begin{array}{l}\text { Line Fol- } \\
\text { lower Sen- } \\
\text { sor }\end{array}$ & $\begin{array}{l}\text { Ultrasonic } \\
\text { Sensor }\end{array}$ & $\begin{array}{l}\text { Infrared } \\
\text { Obstacle } \\
\text { Detector }\end{array}$ \\
\hline Reference & TCRT5000 & HC-SR04 & FC-51 \\
\hline Detection Distance & $\begin{array}{l}1 \mathrm{~mm}-25 \\
\mathrm{~mm}\end{array}$ & $2 \mathrm{~cm}-4 \mathrm{~m}$ & $\begin{array}{l}2 \mathrm{~cm}-30 \\
\mathrm{~cm}, \text { Angle: } \\
35\end{array}$ \\
\hline Operating Voltage & $5 \mathrm{~V}$ & $5 \mathrm{~V}$ & $3.3-5 \mathrm{~V}$ \\
\hline Quantity & 5 & 1 & 1 \\
\hline
\end{tabular}

\subsection{Results and discussion}

The aim of the first and second scenarios was the dissemination of a warning message indicating the presence of an obstacle in the path ahead, using V2V communication. First, the authors tried to move the robots following a map (pre-programmed distances), but since the motors are not completely identical, they ran at different speeds. Consequently, the car couldn't move forward in a straight movement. For that reason, the authors added line follower sensors, to keep the car on the line (road).

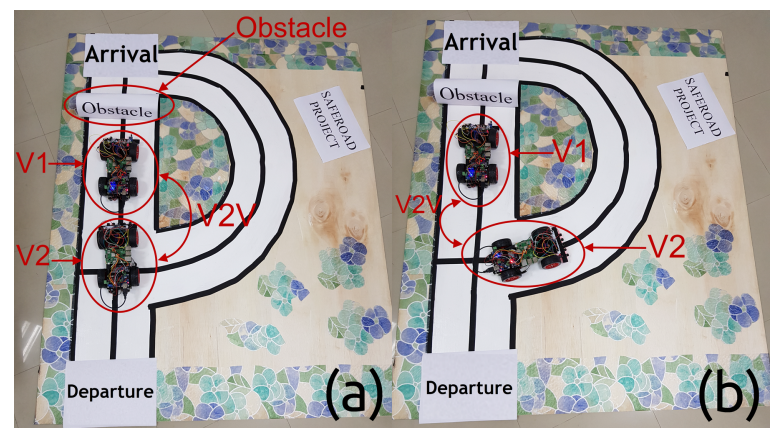

Figure 7: (a) The first scenario (V2V communication): V2 stops, once receiving the alert from V1 indicating the presence of an obstacle. (b) The second scenario (V2V communication): V2 changes the road, once receiving the alert from V1 indicating the presence of an obstacle.

In the first scenario, V1 and V2 ran at the same time on a straight path, and an obstacle was placed just before the destination. V1 is equipped with an infrared sensor (see Fig. 6(a)), which detect the obstacle. Once the obstacle is detected, V1, which plays the role of the client, stops immediately, and sends the data to the server (V2) as a warning notification, using the Wi-Fi interface. As soon as it receives the warning, V2 stops in its turn (Fig. 7(a)). Receiving the notification depends on the range of the Wi-Fi (the maximum distance between the first and the second car).

Similarly, in the second scenario, V1 and V2 ran at the same time on a straight path, and an obstacle was placed just before the destination. The infrared sensor in V1 (the client) detects the obstacle and stops immediately. It sends then an alert to V2 (the server) to change the road in order to avoid the obstacle, and get to the 
destination. Therefore, once $\mathrm{V} 2$ reaches the intersection, it changes the road taken by the first vehicle and chooses the safe road (Fig. 7 (b)).

For the third scenario, the intention was the sending of the warning message using V2I communication. For this purpose, a third Raspberry Pi board was used with an ultrasonic sensor to play the role of the roadside unit (RSU). In this case, one vehicle was put in the path, and the obstacle was placed on the road. The RSU senses the presence of the obstacle using the ultrasonic sensor (see (b) in Fig. 6. It uses then the Wi-Fi interface to send a warning to the vehicle presented in the zone. As soon as the vehicle reaches the intersection, it takes the safe road (Fig. 8).

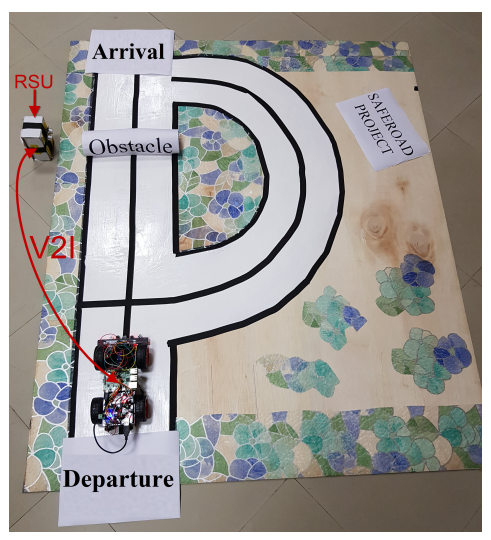

Figure 8: The third scenario (V2I communication): once getting to the intersection, the vehicle will take the other road, thanks to the alert received from the RSU.

The realization can be applied in the real world, as can be seen in Fig. 4 which depicts an example of Kenitra city where the area mentioned is likely to have accidents. The presence of the RSUs in this zone can help to avoid accidents. The RSU detects the crash and sends the alert to the vehicles in the area and also to the nearby RSUs. Another type of obstacles that can be detected using RSUs is the slowed traffic, as it is illustrated in Fig. 3 . The communication between the RSUs in the area can help Moroccan drivers to avoid the traffic jam by taking another road where the traffic is relatively fast.

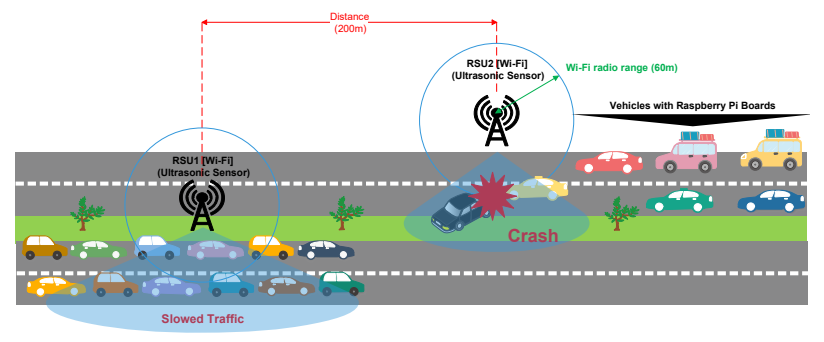

Figure 9: Summary of the contribution to Moroccan roads.

As explained above, the application of the system in real life in Morocco can play an important role in addressing the issues of road safety. It can be used to serve to avoid accidents, as it can also be useful to avoid slowed traffic. Fig. 9 summarizes the contribution of the system in Moroccan roads. In the first direction, the RSU2 detects the crash and sends an alert to nearby vehicles using the Wi-Fi interface. In the opposite way, the RSU1 detects the slowed traffic and sends a warning to the vehicles in the zone. The two RSUs can also communicate by sending information about the traffic in the two directions.

From Fig. 9 it can be seen that the crash was caused by a vehicle that took the lane in the opposite way. In order to resolve this kind of situation, the authors made another proposition to the METLE. They suggest building the new roads without a separation between the lanes of the opposite directions. Therefore, in the case of an accident or traffic jams, it will be possible to use a lane or more in the opposite direction to alleviate the traffic (see Fig. 10 and Fig. 11).

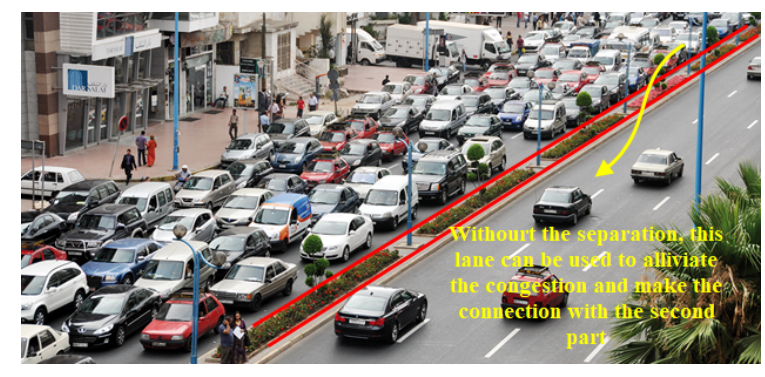

Figure 10: Road with separation between opposite lanes - Morocco

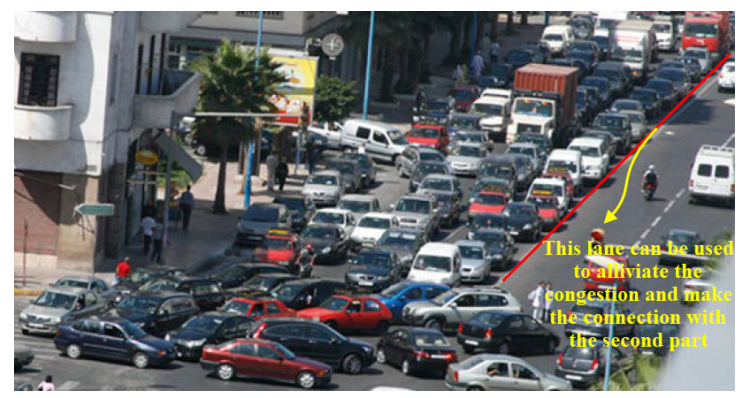

Figure 11: Road without separation between opposite lanes - Morocco

Due to V2I communication, the RSU will detect the obstacle (accident), send a warning to inform the nearby drivers and send also a notification to the traffic management center (direction of the roads or gendarmerie). Consequently, the center will change the light panels to indicate the use of additional lanes. The drivers will then keep the correct lane.

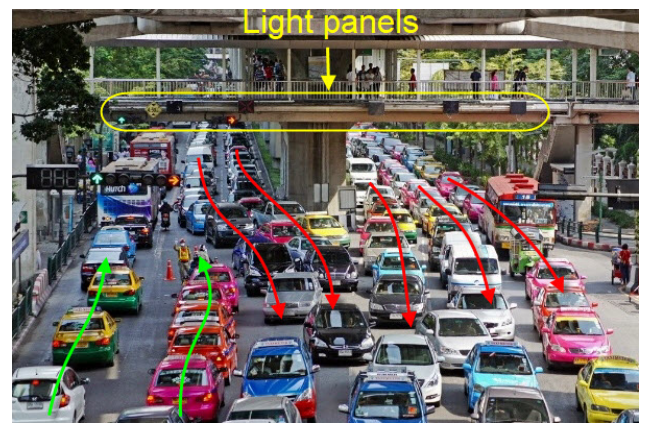

Figure 12: Avoiding Traffic Jams in Bangkok, Thailand by adding opposit lanes using the light panels

\footnotetext{
${ }^{3}$ https://www.shutterstock.com/video/clip-17081557-bangkok-thailand-june-2016-traffic-jam (accessed Oct. 01, 2019).
} 
An example of Bangkok city ${ }^{3}$ in Thailand is illustrated in Fig. 12. The road contains six lanes, but two of them were added in the opposite direction to mitigate the congestion. This is one of the propositions that can be made in the Moroccan case to solve rush hour problems, especially in big cities.

\section{Conclusion}

The main concern of the paper was to present an implementation of vehicular communications using both V2V and V2I technologies. The goal was to notify the driver at the right time so that he can take the navigation choice depending on the received alert. The tests were conducted using the Raspberry Pi 3 boards, model B and model $\mathrm{B}+$, in addition to a specific number of sensors. Two mini cars were used to realize $\mathrm{V} 2 \mathrm{~V}$ communication by testing two different scenarios which worked well. Authors realized also the V2I communication which worked as well. In addition to that, they made proposals to the Ministry of transportation concerning the deployment of the RSUs and the management of traffic jams in Kenitra City. Based on the results, it can be concluded that these scenarios can be used in the field of road safety, related to the Moroccan case, to address the problems of transportation in kenitra city for example. This will decrease the number of accidents in Morocco and help save lives. As the current work may have some limitations that can be faced in real life, the authors intend in future research to conduct real experiments using two real vehicles. This will reveal all the limitations and lead to a complete system. Further research could bear from this work, such as the integration of cameras in this system in order to study different scenarios of accidents.

Conflict of Interest The authors declare no conflict of interest.

\section{References}

[1] Z. Sabir, S. Dafrallah, A. Amine, "A Novel Solution to Prevent Accidents using V2I in Moroccan Smart Cities," in 2019 International Conference on Computational Intelligence and Knowledge Economy (ICCIKE), 621-625, Dubai, UAE, 2019, doi:10.1109/ICCIKE47802.2019.9004397.

[2] F. Losilla, A.-J. Garcia-Sanchez, F. Garcia-Sanchez, J. Garcia-Haro, Z. J. Haas, "A Comprehensive Approach to WSN-Based ITS Applications: A Survey," Sensors, 11(11), 10220-10265, 2011, doi:10.3390/s111110220.

[3] L. a. W. Ministry of Equipment, Transport, D. of Roads, "Recueil Des Statistiques Des Accidents Corporels De La Circulation Routière," 2016.

[4] N. C. for the Prevention of Traffic Accidents, Guide référenciel pour la planification de sécurité routière dans les zones urbaines, Editions \& Impressions Bouregreg, Rabat, 1st edition, 2017.

[5] J. A. Guerrero-Ibáñez, C. Flores-Cortés, S. Zeadally, "Vehicular Ad-hoc Networks (VANETs): Architecture, Protocols and Applications," in N. Chilamkurti, S. Zeadally, H. Chaouchi, editors, Next-Generation Wireless Technologies, 49-70, Springer, London, 2013, doi:10.1007/978-1-4471-5164-7_5.

[6] Z. Sabir, A. Amine, "Connected vehicles using NDN for intelligent transportation systems," in International Conference on Industrial Engineering and Operations Management, volume 2018, 2433-2441, Paris, France, 2018.
[7] Z. Sabir, A. Amine, "NDN vs TCP/IP: Which One Is the Best Suitable for Connected Vehicles?" in Recent Advances in Mathematics and Technology, Applied and Numerical Harmonic Analysis, 151-159, Springer International Publishing, Cham, 2020, doi:10.1007/978-3-030-35202-8_9.

[8] R. Brookes, P. Pagani, "What becomes a car," in Proposed Paper for: BIT 2014 Conference Workshop-Technology Enabled Business Models: Platforms, Analytics and Performance, 2014.

[9] H. Ullah, N. Gopalakrishnan Nair, A. Moore, C. Nugent, P. Muschamp, M. Cuevas, "5G Communication: An Overview of Vehicle-to-Everything, Drones, and Healthcare Use-Cases," IEEE Access, 7, 37251-37268, 2019, doi:10.1109/ACCESS.2019.2905347.

[10] K. Kuramoto, K. Fujimura, T. Hasegawa, "The Multi-Class Zone ITS Communication Scheme for Real-time Communications in Intersections," in 2007 IEEE Intelligent Transportation Systems Conference, 431-435, 2007, doi: 10.1109/ITSC.2007.4357804.

[11] N. Taherkhani, S. Pierre, "Centralized and Localized Data Congestion Control Strategy for Vehicular Ad Hoc Networks Using a Machine Learning Clustering Algorithm," IEEE Transactions on Intelligent Transportation Systems, 17(11), 3275-3285, 2016, doi:10.1109/TITS.2016.2546555.

[12] J. Santa, A. F. Gomez-Skarmeta, "Sharing Context-Aware Road and Safety Information," IEEE Pervasive Computing, 8(3), 58-65, 2009, doi:10.1109/ MPRV.2009.56.

[13] K.-C. Su, H.-M. Wu, W.-L. Chang, Y.-H. Chou, "Vehicle-to-Vehicle Communication System through Wi-Fi Network Using Android Smartphone," in 2012 International Conference on Connected Vehicles and Expo (ICCVE), 191-196, 2012, doi:10.1109/ICCVE.2012.42.

[14] K. C. Dey, A. Rayamajhi, M. Chowdhury, P. Bhavsar, J. Martin, "Vehicle-tovehicle (V2V) and vehicle-to-infrastructure (V2I) communication in a heterogeneous wireless network " Performance evaluation," Transportation Research Part C: Emerging Technologies, 68, 168-184, 2016, doi:10.1016/j.trc.2016.03. 008.

[15] X. Huang, D. Zhao, H. Peng, "Empirical Study of DSRC Performance Based on Safety Pilot Model Deployment Data," IEEE Transactions on Intelligent Transportation Systems, 18(10), 2619-2628, 2017, doi:10.1109/TITS.2017. 2649538.

[16] Y. Du, M. Chowdhury, M. Rahman, K. Dey, A. Apon, A. Luckow, L. B. Ngo, "A Distributed Message Delivery Infrastructure for Connected Vehicle Technology Applications," IEEE Transactions on Intelligent Transportation Systems, 19(3), 2018, doi:10.1109/TITS.2017.2701799.

[17] N. G. Ghatwai, V. K. Harpale, M. Kale, "Vehicle to vehicle communication for crash avoidance system," in 2016 International Conference on Computing Communication Control and automation (ICCUBEA), 1-3, 2016, doi: 10.1109/ICCUBEA.2016.7860118.

[18] S. A. Hadiwardoyo, S. Patra, C. T. Calafate, J. Cano, P. Manzoni, "An Android ITS Driving Safety Application Based on Vehicle-to-Vehicle (V2V) Communications," in 26th International Conference on Computer Communication and Networks (ICCCN), 1-6, 2017, doi:10.1109/ICCCN.2017.8038486.

[19] S. Tayeb, M. Pirouz, S. Latifi, A Raspberry-Pi Prototype of Smart Transportation, IEEE Computer Society, 2017, doi:10.1109/ICSEng.2017.25, pages: 176-182.

[20] V. Vibin, P. Sivraj, V. Vanitha, "Implementation of In-Vehicle and V2V Communication with Basic Safety Message Format," in 2018 International Conference on Inventive Research in Computing Applications (ICIRCA), 637-642, 2018, doi:10.1109/ICIRCA.2018.8597311.

[21] S. Dafrallah, A. Amine, S. Mousset, A. Bensrhair, "Will Capsule Networks overcome Convolutional Neural Networks on Pedestrian Walking Direction?" in The 22nd IEEE International Conference on Intelligent Transportation Systems (ITSC), Auckland, New Zealand, 2019, doi:10.1109/ITSC.2019.8917019. 